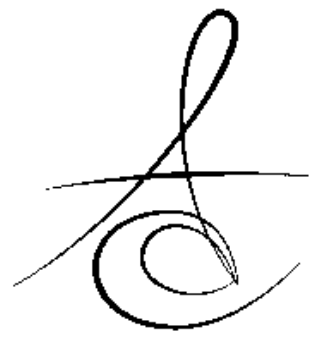

\title{
SİKLOSPORİN-A VE AMLODİPİN KULLANIMINA BAĞLI DİŞETİ BÜYÜMESİNİN ND:YAG LAZERLE TEDAVİSI: OLGU SUNUMU
}

\section{TREATMENT OF CYCLOSPORIN A AND AMLODIPINE INDUCED GINGIVAL OVERGROWTH WITH ND:YAG LASER ( CASE REPORT)}

Araş. Gör. Dr. Gülnihal Emrem DOĞAN* Araş. Gör. Dt. Ebru SAĞLAM*

Doç. Dr. Mehmet Cankat KARA**

Doç. Dr. Turgut DEMİR*

Makale Kodu/Article code: 1314

Makale Gönderilme tarihi: 18.09.2013

Kabul Tarihi: 06.01 .2014

\section{ÖZET}

Organ transplantasyonlarında kullanılan temel bir immünosüpresan olan siklosporin-A (Cs-A) ve antihipertansif amlodipinin kullanımına bağlı oral komplikasyonlar gelişebilmektedir. Bu komplikasyonların en yaygın olanlarından biri dişeti büyümeleridir. $\mathrm{Bu}$ olgu, böbrek transplantasyonu nedeni ile uzun dönem Cs-A ve amplodipin kullanımı sonucu dişeti büyüme şikayeti gelişen bir hastanın tedavi öncesi ve sonrası klinik durumunu ortaya koymaktadır. Sunulan vakada aşırı büyüyen dişeti dokularında $\mathrm{Nd}$ : YAG lazerle yapılan cerrahi işlemi takiben dikkatli plak kontrolü ile dişeti dokusunda yeterli ölçüde iyileşme sağlanmıştır. Cerrahide Nd: YAG lazer kullanımı cerrahi sonrası gelişebilen kanama, ağrı gibi komplikasyonları azaltmıştır.

Anahtar Kelimeler: Siklosporin-A, Amlodipin, Dişeti Büyümesi, Nd:YAG Lazer

\section{GİRİş}

İlaca bağlı dişeti büyümeleri hem hasta hem hekim için ciddi bir sorundur. Antikonvülsanlar, kalsiyum kanal blokörleri (KKB) ve immünsüpresanlar dişeti büyümelerine sebep olduğu bilinen üç temel ilaç sınıfıdır. ${ }^{1-3}$ İmmünosüpresan olarak transplantasyon sonrası organ reddinin önlenmesi amacıyla hastalara genellikle siklosporin-A (Cs-A) kullandırılmaktadır. CsA'nın en önemli oral yan etkisi dişeti büyümesidir. ${ }^{4-6}$ Cs-A' ya bağlı olarak aynı zamanda hipertansiyon da gelişebilmektedir. Bu nedenle Cs-A kullanan birçok

\section{ABSTRACT}

Oral complications may develop due to use of immunosuppresant cyclosporine-A (Cs-A), which is basic drug in organ transplantation, and antihypertensive amlodipine. One of the most common of these complications is gingival overgrowth. This case demonstrates clinical status of a patient before and after the treatment, who has developing gingival overgrowth complaint after long-term use of amlodipine and Cs-A because of kidney transplantation. In the presented case, sufficient improvement of gingival tissues was provided by careful plaque control following surgical procedures with Nd: YAG laser in excessive gingival overgrowth tissues. Rising complications after surgical operations such as bleeding and pain can decrease by use of $\mathrm{Nd}$ : YAG laser.

Key Words: Cyclosporine-A, Amlodipine, Gingival Overgrowth, Nd-YAG Laser

böbrek transplantasyon hastasına ek olarak antihipertansif tedavi gerekmektedir. Antihipertansif tedavide sıklıkla kullanılan nifedipin ve amlodipin gibi KKB ilaçlar da dişeti büyümelerine sebep olabilir. ${ }^{7}$ Nifedipin kullanımı sonrası dişeti büyümeleri sıklıkla oluşurken, amplodipin kullanımına bağlı büyümelerin nadiren görüldüğü bildirilmiştir. ${ }^{1,8}$

Günümüzde ilaca bağlı dişeti büyümelerinin tedavisinde büyümenin şiddetine ve fibrotik durumuna göre konvansiyonel periodontal tedavi, oral hijyen eğitimi ile birlikte periodontal flep, gingivektomi

\footnotetext{
* Atatürk Üniversitesi, Diş Hekimliği Fakültesi, Periodontoloji A.D.

**Ordu Üniversitesi, Diş Hekimliği Fakültesi, Periodontoloji A.D.

${ }^{\#}$ Bu makale; Türk Periodontoloji Derneği 40. Bilimsel Kongresi İzmir, 44-16 Mayıs 2010'de poster olarak sunulmuştur.
} 
operasyonları, elektrocerrahi ve dental lazer uygulamaları yapılmaktadır. $^{9}$ Yumuşak dokuları ilgilendiren bu tip cerrahi tedavilerde bistüri yerine lazerlerin kullanımı ile cerrahi sonrası komplikasyon görülme insidansı azalmaktadır. ${ }^{10}$

$\mathrm{Bu}$ vakada, Cs-A ve amlodipin kullanımına bağlı gelişen dişeti büyümelerinin klinik özellikleri ve Nd:YAG lazer ile tedavisi sunulmaktadır.

\section{OLGU SUNUMU}

Bypass ve sonrasında böbrek transplantasyon ameliyatları geçiren tip 1 diabet ve hipertansiyon hastası 51 yaşındaki erkek hasta dişeti sorunları nedeni ile kliniğimize başvurdu. Hasta mevcut hastalıklarından ve geçirdiği operasyonlardan dolayı, Coraspin (asetilsalisilik asit, 100 mg/gün), Sandimmün-neoral (siklosporin, $300 \mathrm{mg} / \mathrm{gün}$ ), beloc (47,5 mg metoprolol süksinat), Deltacortril (5 mg prednizolon) ve Amlodis (10 $\mathrm{mg}$ amplodipin) kullanmaktaydı.

Hastanın klinik muayenesinde oral hijyeninin oldukça kötü olduğu $\left(\mathrm{GI}^{11}=2,7 ; \mathrm{PI}^{12}=2,5\right)$, ayrıca alt ve üst çenede ön bölge dişetlerinde ağrısız, sondalamada kanayan, koyu kırmızı renkte büyümeler gözlendi (Resim 1). Ağız hijyeninin kötü olmasına, yaygın supra ve subgingival diştaşlarının bulunmasına rağmen dişeti büyümelerinin ilaçları kullanmaya başladıktan sonra geliştiği öğrenildi. Dişeti büyümesinin görüldüğü bölgelerde $7-9$ mm'lik miks cepler ölçüldü. Hastaya oral hijyen eğitimi verilerek konsültasyon bilgileri doğrultusunda periodontal başlangıç tedavileri yapıldı. Hastanın oral hijyeni sağlanarak cerrahi işlem için başlangıç tedavisinden sonra 8 hafta beklendi. Hastanın coraspin kullanımı cerrahi uygulamadan 5 gün öncesinde kesilerek, hastaya işlemlerden 1 saat öncesinde 2 gr profilaktik amaçlı amoksisilin+klavulonik asit içeren antibiyotik kullandırıldı. Hastanın üst ve alt çene hiperplastik dişeti dokuları, Nd: YAG lazerle (Smarty A10; DEKA, Firenze, Italy: $1064 \mathrm{~nm}$ ); güç çıkışı, $3.2 \mathrm{~W}$; enerji, $80 \mathrm{~mJ}$; frekans, $40 \mathrm{~Hz}$ değerlerinde kullanılarak eksize edildi (Resim-2). Alınan dokuların histopatolojik değerlendirmesinde parakeratozis ve akantozis gösteren kalınlaşmış epitelyum tabakası, düzensiz retepegler ve inflamatuar hücre infiltrasyonu gözlendi. Bulgular ışığında kronik enflamatuar dişeti büyümesi olarak teşhis konuldu. Nd: YAG lazerle yapılan operasyon sırasında kanama gözlenmedi. Operasyon sonrası 3., 7., 15. ve 30. günlerde kontroller yapıldı (Resim-3,4,5). Hastadan alınan bilgide postoperatif dönemde herhangi bir ağrı olmadığı ve çiğneme, konuşma, diş fırçalama gibi rutin fonksiyonlarda da bir sıkıntı yaşamadığı öğrenildi.

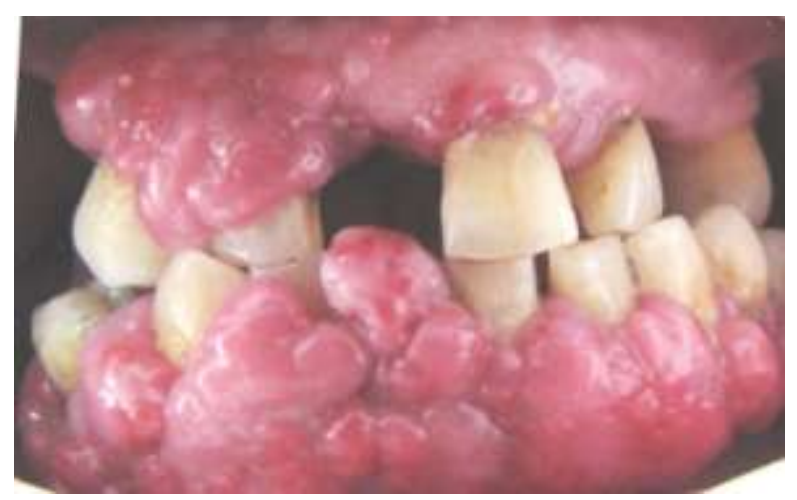

Resim1. Tedavi öncesi ağız içinin klinik görünümü

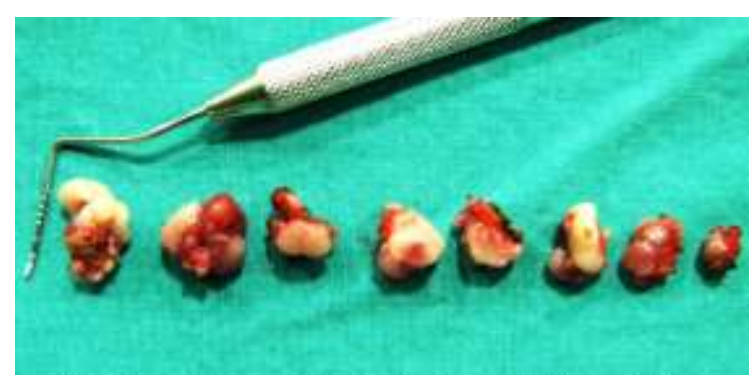

Resim 2. Eksize edilen gingival dokular

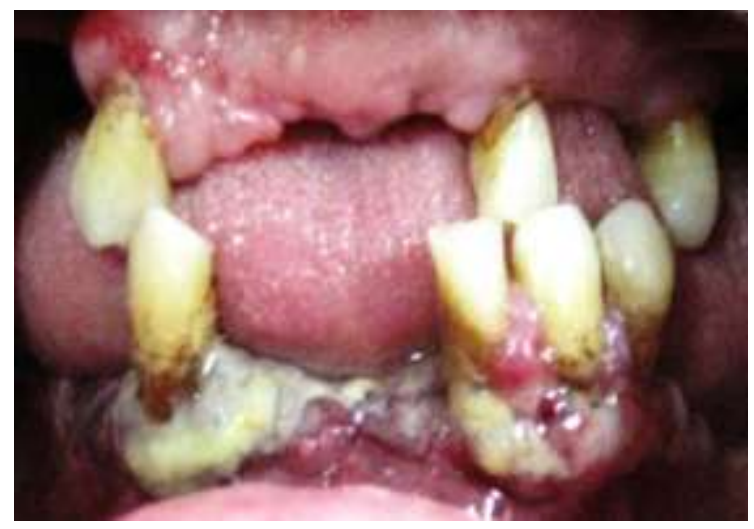

Resim 3. Operasyondan 5 gün sonra 


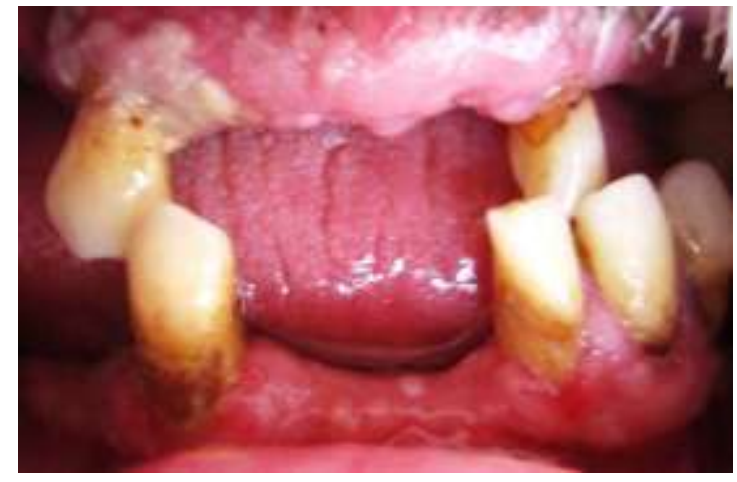

Resim 4. Operasyondan 15 gün sonra

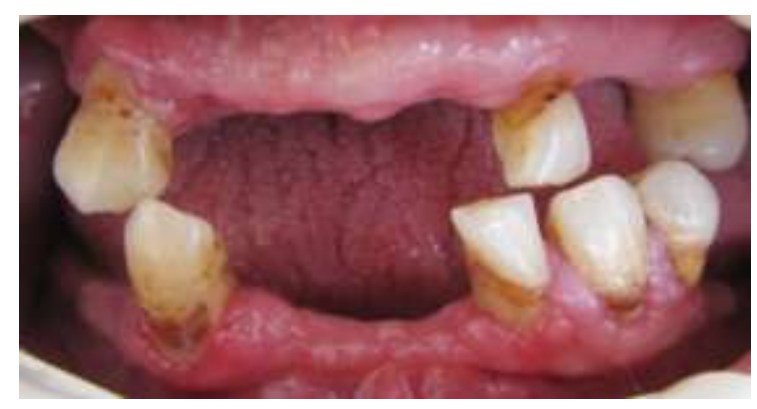

Resim 5. Operasyondan 1 ay sonra

\section{TARTIŞMA}

İlaca bağlı dişeti büyümesi, böbrek transplantasyonu sonrasında CSA ve KKB kullanan hastalarda önemli bir problemdir. Dişeti büyümesi beslenmeyi zorlaştırır ve görünümü olumsuz yönde etkiler. ${ }^{13}$

İlaca bağlı dişeti büyümelerinin prevelansı etken olan ilacın cinsine göre değişiklik göstermektedir. CSA ile ilişkili dişeti büyümelerinin genel preve lansının farklı çalışmalarda \%8-81 arasında değişiklik gösterdiği ortaya konmuştur. ${ }^{14}$ Amlodipin için ise dişeti büyümelerinin prevelansı $\% 1,7-3,3$ olarak bildirilmektedir. ${ }^{15,}{ }^{16}$ Sunulan vakada olduğu gibi dişeti büyümelerinin CSA ve KKB'lerini birlikte kullanan hastalarda, sadece CSA kullanan hastalara göre daha şiddetli olduğu rapor edilmiştir.7

Nifedipine bağlı dişeti büyümesine yaklaşık $\% 10$ oranında rastlamasına rağmen ${ }^{8}$ amlodipine bağlı dişeti büyümesine literatürde oldukça az rastlanmaktadır. $^{8,16,17}$ Jorgensen ${ }^{16}$, yaptığı çalışma sonucunda 5 $\mathrm{mg} / \mathrm{gün}$ amlodipinin 6 aydan fazla kullanılsa bile dişeti büyümesi oluşturmadığını bildirmiştir. Lafzi ve ark.' $1^{1}$ sundukları vakada ise iki ay boyunca tek doz $5 \mathrm{mg} /$ gün amlodipin kullanan hastada dişeti büyümesi olduğunu rapor etmişlerdir. Bizim vakamızda ise hasta yirmi

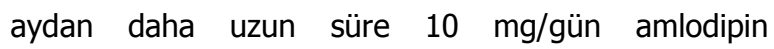
kullanmışır.

İlaca bağlı dişeti büyümesinin asıl etyolojisi bilinmemekle birlikte birçok farklı etken olabileceği düşünülmektedir. İlacın konsantrasyonu, dozu, kullanım süresi, kişinin yaşı, cinsiyeti, oral hijyen durumu, lokal anatomik etkenler, transplantasyondan önce var olan hiperplazi ve genetik faktörler dişeti büyümesi ile ilişkili olabilir. ${ }^{13,}{ }^{18}$ Gençlerin yaşılıara, erkeklerin kadınlara göre dişeti büyümelerine daha yatkın olduğu bildirilmiştir. ${ }^{13}$ Dişeti büyümeleriyle terapötik doz aralı̆ı̆nda kullanılan siklosporinin dozu veya serum konsantrasyonundan daha fazla ilişkili olan etken dental plağın varlığıdır. ${ }^{18,19}$ Dişeti iltihabının da dişeti büyümeleri için bir risk faktörü olduğu ileri sürülmüştür. ${ }^{20}$ Bununla birlikte günümüzde dişeti iltihabı ile dişeti büyümeleri arasındaki ilişki hala tartışılmakta olup dişeti iltihabının neden mi yoksa sonuç mu olduğu henüz belirlenememiştir. ${ }^{21,}{ }^{22}$ Vakamızda 51 yaşındaki erkek hastamızın dişeti büyümelerine etken olabilen ilaçları kullanması yanında kötü oral hijyene sahip olması dişeti büyümesinin şiddetini artırmış olabilir.

Dokuların cerrahi olarak eksizyonu operasyon sırasında şiddetli kanamaya neden olabilmektedir. Bu amaçla Darbar ve ark. ${ }^{23}$ dişeti büyümelerinin geleneksel cerrahi eksizyonu sonucu hemostazın sağlanmasına yardımc olmak amacıyla akrilik stentlerin kullanımını önermişlerdir. Bizim vakamızda oluşabilecek kanamayı azaltmak için lazer kullanımı tercih edilmiş̧ir. Bistüri ile karşılaştırılığında lazer ile yapılan eksizyonlarda cerrahi sonrası daha az kanama ve ağrı görülmektedir. ${ }^{24}$ Sinir uçlarını biyolojik bir giysi olarak örten yara yüzeyinde oluşan protein pıhtıya bağlı olarak ağrının azaldığı düşünülmektedir. Literatürde lazer ile yapılan cerrahi sonrası yara iyileşmesi hakkında farklı görüşler mevcuttur. Bazı araştırmacılar lazer ile operasyonda yara iyileşmesinin daha hızı ve daha az skar dokusu ile olacağını belirtirken, bazı araştırmacılar da tam tersi görüşü savunmaktadırlar. ${ }^{10,25,26}$

Sonuç olarak; CsA ve KKB' nin birlikte kullanımı ve kötü oral hijyen dişeti büyümesini şiddetlendirebilmektedir. Şiddetli dişeti büyümesinin lazer ile eksizyonunun operasyon esnasında kanamayı

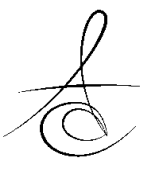


azalttığını ve postoperatif hasta konforunu artırdığını düşünmekteyiz. Lazer ile eksizyonun yara iyileşmesi üzerine etkilerini araştıran ileri çalışmalara intiyaç vardır.

\section{KAYNAKLAR}

1. Lafzi A, Farahani RM, Shoja MA. Amlodipineinduced gingival hyperplasia. Med Oral Patol Oral Cir Bucal, 2006, 11: E480-2.

2. Eggerath J, English $H$, Leichter JW. Drugassociated gingival enlargement: case report and review of aetiology, management and evidencebased outcomes of treatment. J N Z Soc Periodontol, 2005: 7-14.

3. Kara c, Yağız H, Zihni M. Nifedipin tedavisine bağlı ortaya çıkan dişeti büyümesi (Olgu Sunumu). Atatürk Üni Diş Hek Fak Derg 2006;16(1):59-62.

4. Callaghan $\mathrm{CJ}$, Bradley JA. Current status of renal transplantation. Methods Mol Biol, 2006, 333: 128.

5. Gourishankar S, Halloran PF. Late deterioration of organ transplants: a problem in injury and homeostasis. Curr Opin Immunol, 2002, 14: 57683.

6. Hariharan $\mathrm{S}$, Johnson $\mathrm{CP}$, Bresnahan BA, Taranto $\mathrm{SE}$, McIntosh MJ, Stablein D. Improved graft survival after renal transplantation in the United States, 1988 to 1996. N Engl J Med, 2000, 342: 605-12.

7. Lopez-Pintor RM, Hernandez G, de Arriba L, Morales JM, Jimenez C, de Andres A. Amlodipine and nifedipine used with cyclosporine induce different effects on gingival enlargement. Transplant Proc, 2009, 41: 2351-3.

8. Seymour RA, Ellis JS, Thomason JM, Monkman S, Idle JR. Amlodipine-induced gingival overgrowth. J Clin Periodontol, 1994, 21: 281-3.

9. Camargo PM CF, Takei HH. , Treatment of gingival enlargement. 11 ed.; St. Louis, Missouri, 2011; p 556-61.

10. Mattson JS, Blankenau R, Keene JJ. Use of an argon laser to treat drug-induced gingival overgrowth. The Journal of the American Dental Association, 1998, 129: 78-83.

11. Loe H, Silness J. Periodontal Disease in Pregnancy. I. Prevalence and Severity. Acta Odontol Scand, 1963, 21: 533-51.
12. Silness J, Loe H. Periodontal Disease in Pregnancy. Ii. Correlation between Oral Hygiene and Periodontal Condtion. Acta Odontol Scand, 1964, 22: 121-35.

13. Radwan-Oczko M, Boratynska M, Klinger M, Zietek M. Risk factors of gingival overgrowth in kidney transplant recipients treated with cyclosporine $A$. Ann Transplant, 2003, 8: 57-62.

14. Hernandez G, Arriba L, Frias MC, de la Macorra JC, de Vicente JC, Jimenez $C$, de Andres A, Moreno E. Conversion from cyclosporin $A$ to tacrolimus as a non-surgical alternative to reduce gingival enlargement: a preliminary case series. $J$ Periodontol, 2003, 74: 1816-23.

15. Ellis JS, Seymour RA, Steele JG, Robertson P, Butler TJ, Thomason JM. Prevalence of gingival overgrowth induced by calcium channel blockers: a community-based study. J Periodontol, 1999, 70: 63-7.

16. Jorgensen MG. Prevalence of amlodipine-related gingival hyperplasia. J Periodontol, 1997, 68: 6768.

17. Ellis JS, Seymour RA, Thomason JM, Monkman SC, Idle JR. Gingival sequestration of amlodipine and amlodipine-induced gingival overgrowth. Lancet, 1993, 341: 1102-3.

18. Lin YT, Yang FT. Gingival enlargement in children administered cyclosporine after liver transplantation. J Periodontol, 2010, 81: 1250-5.

19. Thomas DW, Newcombe RG, Osborne GR. Risk factors in the development of cyclosporine-induced gingival overgrowth. Transplantation, 2000, 69: 522-6.

20. Nurmenniemi PK, Pernu HE, Laukkanen $P$, Knuuttila ML. Macrophage subpopulations in gingival overgrowth induced by nifedipine and immunosuppressive medication. J Periodontol, 2002, 73: 1323-30.

21. Lima RB, Benini V, Sens YA. Gingival overgrowth in renal transplant recipients: a study concerning prevalence, severity, periodontal, and predisposing factors. Transplant Proc, 2008, 40: 1425-8.

22. Aimetti M, Romano F, Priotto P, Debernardi C. Non-surgical periodontal therapy of cyclosporin A gingival overgrowth in organ transplant patients. Clinical results at 12 months. Minerva Stomatol, 2005, 54: 311-9. 
23. Darbar UR, Hopper C, Speight PM, Newman HN. Combined treatment approach to gingival overgrowth due to drug therapy. $J$ Clin Periodontol, 1996, 23: 941-4.

24. Kara C. Evaluation of patient perceptions of frenectomy: a comparison of $\mathrm{Nd}$ :YAG laser and conventional techniques. Photomed Laser Surg, 2008, 26: 147-52.

25. Pogrel MA, Yen CK, Hansen LS. A comparison of carbon dioxide laser, liquid nitrogen cryosurgery, and scalpel wounds in healing. Oral Surg Oral Med Oral Pathol, 1990, 69: 269-73.

26. White JM, Goodis HE, Rose CL. Use of the pulsed $\mathrm{Nd}$ :YAG laser for intraoral soft tissue surgery. Lasers Surg Med, 1991, 11: 455-61.

\author{
Yazışma Adresi \\ Gülnihal Emrem Doğan \\ Atatürk Üniversitesi, \\ Diş Hekimliği Fakültesi, \\ Periodontoloji A.D. \\ Erzurum, Türkiye \\ Telf: (0904422311902, \\ Fax: 0904422360945, \\ E-mail: gulnihalemrem@hotmail.com)
}

